\title{
PENGARUH SISTEM OLAH TANAH DAN APLIKASI MULSA BAGAS TERHADAP POPULASI DAN BIOMASSA CACING TANAH PADA PERTANAMAN TEBU (Saccharum officinarum L.) RATOON KE-2
}

\author{
Alexander Sibuea, Sri Yusnaini, Ainin Niswati \& Dermiyati \\ Jurusan Agroteknologi, Fakultas Pertanian Universitas Lampung, \\ Jl. Prof. SoemantriBrodjonegoro, No. 1, Bandar Lampung 35145 \\ Email : sibuealex@yahoo.co.id
}

\begin{abstract}
ABSTRAK
Penelitian ini bertujuan untuk mempelajari pengaruh sistem olah tanah (TOT) dan aplikasi mulsa bagas pada lahan pertanaman tebu (Saccharum officinarum L.) terhadap populasi dan biomassa cacing tanah di PT Gunung Madu Plantations, Lampung Tengah pada ratoon 2. Penelitian ini dilaksanakan pada bulan Juni 2013. Percobaan dilakukan di lahan pertanaman tebu PT Gunung Madu Plantations dengan perlakuan sistem olah tanah dan aplikasi limbah pabrik gula jangka panjang dari tahun 2010 sampai dengan tahun 2020. Analisis cacing tanah dilakukan di Laboratorium Biologi Ilmu Tanah dan analisis contoh tanah dilakukan di Laboratorium Ilmu Tanah, Fakultas Pertanian, Unversitas Lampung. Penelitian ini dilakukan dengan menggunakan rancangan acak kelompok (RAK) dan disusun secara split plot dengan 5 ulangan. Sebagai petak utama adalah perlakuan sistem olah tanah $(\mathrm{T})$ yaitu $\mathrm{T}_{0}=$ olah tanah intensif, $\mathrm{T}_{1}=$ tanpa olah tanah, dan anak petak dalam penelitian ini adalah penggunaan limbah pabrik gula yaitu : $\mathrm{M}_{0}=$ tanpa mulsa $; \mathrm{M}_{1}=$ mulsa 80 ton $\mathrm{ha}^{-1}$ bagas $(\mathrm{C} / \mathrm{N}$ ratio 86). Data yang diperoleh dianalisis dengan sidik ragam yang sebelumnya telah diuji homogenitas ragamnya dengan Uji Bartlett dan aditivitasnya dengan Uji Tukey. Rata-rata nilai tengah diuji dengan uji BNT pada taraf $1 \%$ dan 5\%. Untuk mengetahui hubungan antara populasi dan biomassa cacing tanah dengan $\mathrm{C}$-organik, $\mathrm{pH}$, kadar air tanah, dan suhu tanah dilakukan uji korelasi. Hasil penelitian menunjukkan bahwa : (1) Sistem olah tanah tidak berpengaruh terhadap populasi dan biomassa cacing tanah pada pertanaman tebu; (2) pengaplikasian mulsa bagas berpengaruh terhadap populasi dan biomassa cacing tanah pada pertanaman tebu; (3) terdapat 2 famili cacing tanah yang didapat dari hasil identifikasi, yaitu famili Megascolecidae dan famili Glossoscolecidae; (4) tidak terdapat interaksi antara sistem olah tanah dan aplikasi mulsa bagas terhadap populasi dan biomassa cacing tanah.
\end{abstract}

Kata kunci : Aplikasi mulsa bagas, cacing tanah, ratoon ke-2, sistem olah tanah.

\section{PENDAHULUAN}

Produksi gula harus selalu ditingkatkan seirimg dengan meningkatnya kebutuhan masyarakat akan gula. Beberapa upaya yang dapat dilakukan untuk meningkatkan produksi gula antara lain dengan pengelolaan tanah yang tepat, melalui sistem olah tanah dan pemupukan yang sesuai, dan tindakan rehabilitasi tanah seperti peggunaan mulsa pada lahan pertanaman tebu.

PT. Gunung Madu Plantations merupakan salah satu perkebunan dan pabrik gula di Lampung yang mengelola tanah ultisol sebagai lahan untuk pertanaman tebu. Dalam penyiapan lahan, PT. Gunung Madu Plantations menerapkan olah tanah intensif yang telah dilakukan selama lebih dari 25 tahun (PT. GMP, 2009). Pengolahan tanah secara terus - menerus ini ternyata menimbulkan dampak negatif yang menyebabkan penurunan kualitas tanah.

Pada lahan yang diolah secara berlebihan akan menyebabkan tanah mengalami pemadatan dan menjadi rawan terhadap erosi dan dapat menyebabkan hilangnya bahan organik. Pengolahan tanah dapat merusak agresi tanah dan meningkatkan degradasi bahan organik (Rovira dan Greacen, 1957, dalam Busyra, 1995). Oleh karena itu sangat diperlukan tindakan perbaikan atau rehabilitasi tanah untuk memperbaiki serta mempertahankan kesuburan tanah. Upaya tersebut antara lain dapat dilakukan dengan cara : (1) penggunaan mulsa sisa tanaman, (2) penggunaan bahan organik, dan (3) olah tanah konservasi (Nursyamsi, 2004).

Salah satu usaha untuk memperbaiki kualitas tanah adalah dengan pemberian mulsa. Di PT GMP, terdapat sisa produksi tanaman tebu yaitu limbah padat berupa ampas tebu (bagasse), limbah padat lain adalah endapan nira yang disebut blotong (filter cake) dan abu. Blotong, abu, dan bagas dimanfaatkan sebagai bahan yang juga diberikan ke dalam tanah (Tiara, 2010).

Kombinasi sistem tanpa olah tanah dan pemberian mulsa diharapkan dapat memperbaiki kualitas tanah yang dapat diindikasikan dengan keberadaan cacing tanah. Pada tahun pertama dan ratoon 1 , populasi dan biomassa 
cacing tanah belum dipengaruhi oleh oleh tanah dan pemberian bagas. Oleh karena itu, penelitian ini dilakukan untuk mengetahui apakah pemberian mulsa bagas dan sistem tanpa olah tanah akan memperbaiki kualitas tanah setelah tiga tahun diberi perlakuan tersebut.

Penelitian ini bertujuan untuk mempelajari pengaruh sistem olah tanah (TOT) dan aplikasi mulsa bagas (BBA) pada lahan pertanaman tebu (Saccharum officinarum L.) terhadap populasi dan biomassa cacing tanah di PT Gunung Madu Plantations, Lampung Tengah pada ratoon 2 .

\section{BAHAN DAN METODE}

Penelitian ini dilaksanakan dari bulan Febuari sampai Juni 2013. Percobaan dilakukan di lahan pertanaman tebu PT Gunung Madu Plantations dengan perlakuan sistem olah tanah dan aplikasi limbah pabrik gula jangka panjang dari tahun 2010 sampai dengan tahun 2020. Alat yang digunakan dalam penelitian ini adalah cangkul, sekop, label, plastik, botol plastik, tali plastik, bambu, nampan, ember, gayung, meteran, patok kayu, karung, pinset, tisu, timbangan elektrik, termometer tanah, dan alat-alat lain untuk analisis tanah. Sedangkan bahan yang digunakan dalam penelitian yaitu limbah padat pabrik gula yaitu bagas, blotong, dan abu (BBA) dan perbandingannya dalam percobaan ini adalah 5:3:1, pupuk Urea, pupuk TSP, pupuk $\mathrm{KCl}$, mustard, formalin, air, contoh tanah, dan bahan-bahan lain untuk analisis C-organik dan $\mathrm{pH}$ tanah.

Penelitian ini dilakukan dengan menggunakan rancangan acak kelompok (RAK) dan disusun secara split plot dengan 5 ulangan. Sebagai petak utama adalah perlakuan sistem olah tanah ( $\mathrm{T})$ yaitu $\mathrm{T}_{0}=$ olah tanah intensif, $\mathrm{T}_{1}=$ tanpa olah tanah, dan anak petak dalam penelitian ini adalah penggunaan limbah pabrik gula yaitu $: \mathrm{M}_{0}=$ tanpa mulsa $; \mathrm{M}_{1}=$ mulsa 80 ton $\mathrm{ha}^{-1}$ bagas $(\mathrm{C} / \mathrm{N}$ ratio 86). Data yang diperoleh dianalisis dengan sidik ragam yang sebelumnya telah diuji homogenitas ragamnya dengan Uji Bartlett dan aditivitasnya dengan Uji Tukey. Rata-rata nilai tengah diuji dengan uji BNT pada taraf $1 \%$ dan $5 \%$. Untuk mengetahui hubungan antara populasi dan biomassa cacing tanah dengan $\mathrm{C}$ organik, $\mathrm{pH}$, kadar air tanah, dan suhu tanah dilakukan uji korelasi.

Pengambilan sampel awal dilakukan pada bulan Febuari 2013 dan pengambilan sampel kedua dilakukan pada bulan Juli 2013. Sampel cacing tanah diambil dengan membuat Monolith yang terletak tepat ditengahtengah disetiap plot percobaan (Susilo dan Karyanto, 2005). Sebelum cacing dihitung, tanah seluas $50 \mathrm{~cm} \mathrm{x}$
$50 \mathrm{~cm}$ ditandai dengan tali plastik kemudian digali dengan kedalaman $20 \mathrm{~cm}$. Secara hati-hati cacing tanah diamati dan dihitung jumlahnya dengan menggunakan metode penghitungan dengan tangan (hand sorting), yaitu dengan memisahkan cacing dari tanah satu persatu. Selanjutnya setelah dicapai kedalaman $20 \mathrm{~cm}$, lubang Monolith tadi disiram dengan larutan mustard $0,175 \%$ sebanyak $1 \mathrm{~L}$ secara perlahan ke seluruh bagian lubang. Selanjutnya ditunggu selama 5 menit dan dilihat kedalam lubang, apakah ada cacing yang keluar dari dalam lubang Monolith. Setiap cacing tanah yang didapat, dimasukkan ke dalam botol yang sudah diberi larutan formalin $4 \%$ dan diberi label sesuai perlakuan. Setelah dibawa ke laboratorium, cacing tanah dicuci dengan air bersih dan dimasukkan kembali ke dalam botol kecil tadi yang berisi formalin $4 \%$ dan cacing tanah siap untuk dihitung populasi, biomassa, dan siap untuk diidentifikasi (Susilo dan Karyanto, 2005). Selanjutnya cacing-cacing tanah yang diperoleh diidentifikasi berdasarkan letak klitelum, yang didasari oleh kunci determinasi cacing tanah modifikasi Kemas.

\section{HASIL DAN PEMBAHASAN}

Hasil pengamatan populasi cacing tanah menunjukkan bahwa perlakuan sistem olah tanah tidak berpengaruh nyata, akan tetapi pemberian mulsa bagas berpengaruh nyata terhadap populasi cacing tanah pada 9 BSR2 dan 12 BSR2 (Tabel 1).

Hasil pengamatan biomassa cacing tanah menunjukkan bahwa perlakuan sistem olah tanah tidak berpengaruh nyata, tetapi aplikasi mulsa bagas berpengaruh nyata terhadap biomassa cacing tanah pada pengambilan sampel 9 BSR2, akan tetapi keduanya tidak berpengaruh nyata pada sampel 12 BSR2 (Tabel 2).

Hasil pengamatan cacing tanah yang didapatkan pada lokasi penelitian menurut kunci determinasi cacing tanah modifikasi Hanafiah (2005), terdapat 2 genus dari 2 famili yang berbeda yaitu genus Pheretima (famili Megascolecidae) dan genus Pontoscolex (famili Glossoscolecidae). Cacing tanah dengan genus Pontoscolex sp (famili Glossoscolecidae) berdasarkan metode identifikasi modifikasi Hanafiah merupakan cacing tanah yang letak klitelum berada pada segmen 14-20 serta memiliki setae yang tersusun menurut pola lumbrisin (berpasangan erat), dengan panjang total tubuh berkisar antara 35-120 mm, diameter 2-4 mm, jumlah seg men berkisar antara 83-215 segmen, warna bagian dorsal coklat kekuningan, warna bagian ventral abu-abu keputihan, warna ujung anterior kekuningan dan warna ujung posterior coklat kekuningan (Gambar 1). 
Tabel 1. Hasil uji lanjut BNT 5\% populasi cacing tanah pada pengambilan sampel 9 BSR2 dan 12 BSR2

\begin{tabular}{ccc}
\hline Perlakuan & $\begin{array}{c}9 \text { BSR2 } \\
\text { ekor } \mathrm{m}^{-2}\end{array}$ & $\begin{array}{c}12 \mathrm{BSR}^{-2} \\
\text { ekor }^{-2}\end{array}$ \\
\hline Tanpa mulsa & $4(1,73) \mathrm{a}$ & $8 \mathrm{a}$ \\
Dengan mulsa & $22(4,26) \mathrm{b}$ & $20 \mathrm{~b}$ \\
\hline BNT 0,05 & 1,56 & 7,11 \\
\hline
\end{tabular}

Keterangan : Angka yang diikuti oleh huruf yang sama tidak berbeda nyata oleh uji BNT pada taraf nyata 5\%, angka dalam kurung menunjukkan hasil transformasi $(\sqrt{x}+0,5)$. Tidak terdapat interaksi antara sistem olah tanah dan aplikasi mulsa bagas terhadap populasi cacing tanah.

Tabel 2. Hasil uji lanjut BNT 5\% biomassa cacing tanah pada pengambilan sampel 9 BSR2

\begin{tabular}{cc}
\hline Perlakuan & $\begin{array}{c}9 \text { B SR2 } \\
\mathrm{g} \mathrm{m}^{-2}\end{array}$ \\
\hline Tanpa mulsa & $1,06(0,80) \mathrm{a}$ \\
Dengan mulsa & $4,68(1,82) \mathrm{b}$ \\
\hline BNT 0,05 & 0,87 \\
\hline
\end{tabular}

Keterangan : Angka yang diikuti oleh huruf yang sama tidak berbeda nyata oleh uji BNT pada taraf nyata $5 \%$, angka dalam kurung menunjukkan hasil transformasi $(\sqrt{x}+$ $0,5)$. Tidak terdapat interaksi antara sistem olah tanah dan aplikasi mulsa bagas terhadap biomassa cacing tanah.
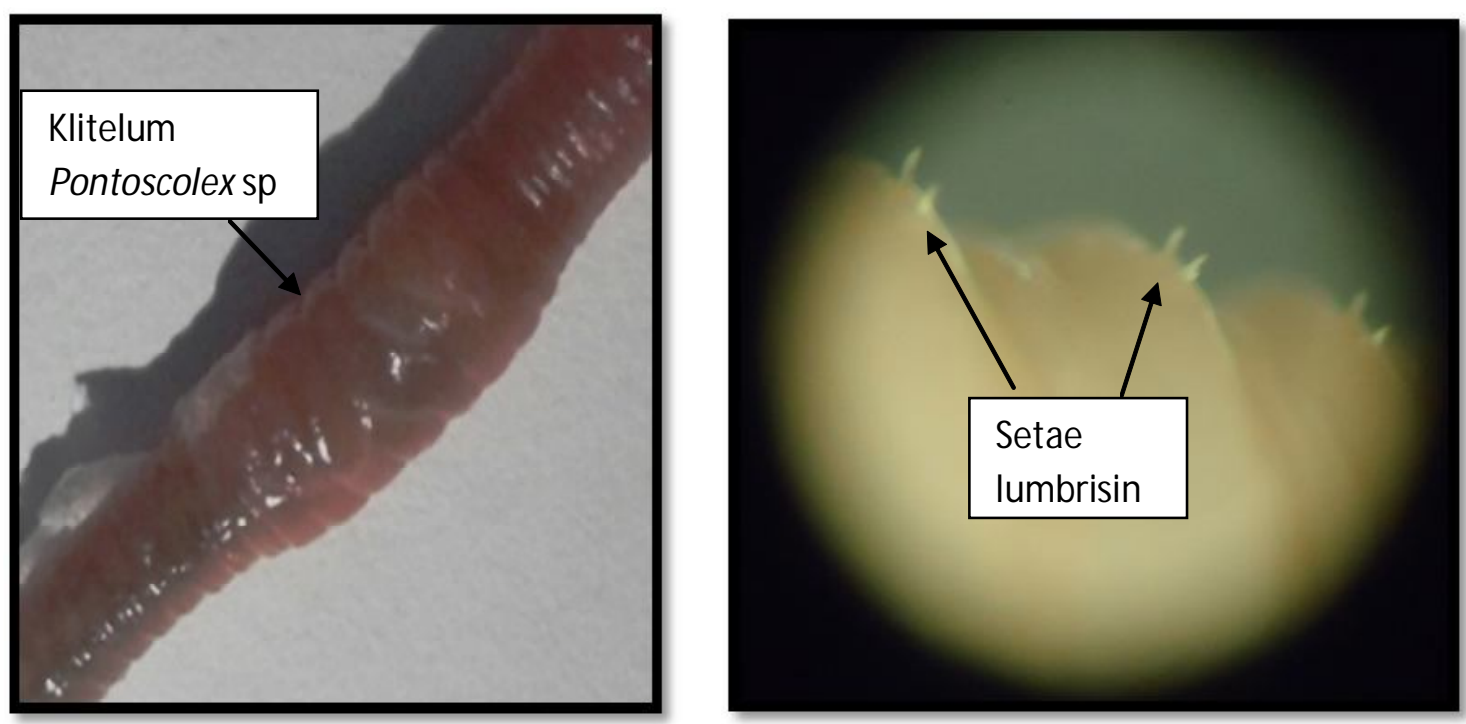

Gambar 1. Hasil identifikasi cacing tanah pada lahan pertanaman tebu, klitelum Pontoscolex sp dan setae lumbrisin
Cacing tanah dengan genus Pheretima sp. (famili Megascolecidae) berdasarkan metode identifikasi modifikasi Hanafiah et al merupakan cacing tanah yang letak klitelum berada di depan segmen ke-15 serta memiliki setae yang tersusun menurut pola perisetin. Susunan pola perisetin terdiri dari banyak setae per segmen (umumnya 12-24 hingga 50-00 setae atau 6 12 hingga 25-50 pasangan lateroventral) (Gambar 2).

Hasil uji korelasi pada Tabel 3 menunjukkan bahwa perlakuan olah tanah dan pemberian mulsa bagas tidak berpengaruh nyata terhadap C-organik, $\mathrm{pH}$, suhu tanah, dan kadar air tanah. Hasil ini sejalan dengan penelitian Suwardjo (1995), yang menyatakan bahwa perlakuan sistem olah tanah tidak memberikan perbedaan kandungan C-organik tanah. Singkatnya waktu penelitian diduga menjadi penyebab tidak berpengaruhnya perlakuan olah tanah terhadap 

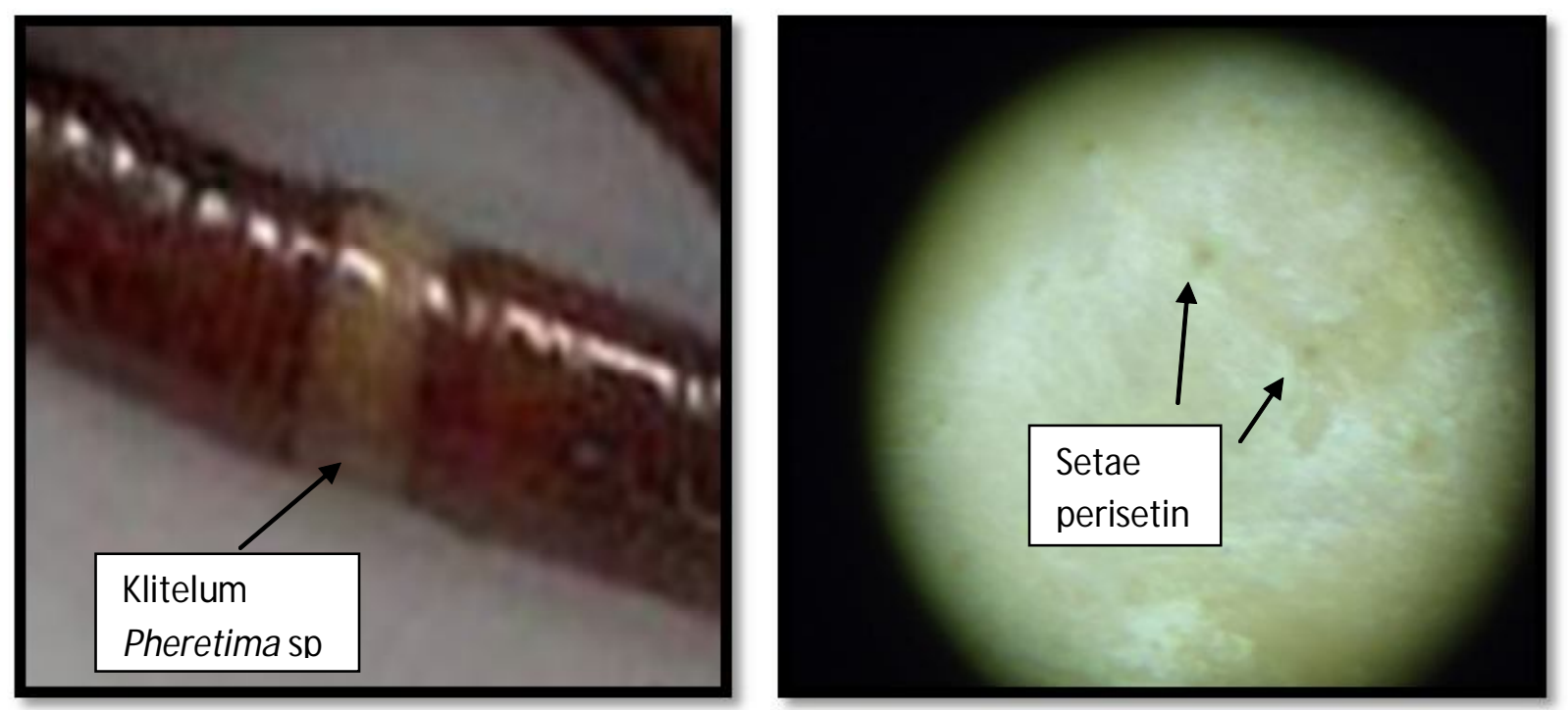

Gambar 2. Hasil identifikasi cacing tanah pada lahan pertanaman tebu, klitelum Pheretima sp dan setae perisetin.

Tabel 3. Hasil uji korelasi antara populasi (ekor $\left.\mathrm{m}^{-2}\right)$ dan biomassa cacing tanah $\left(\mathrm{g} \mathrm{m}^{-2}\right)$ pengambilan sampel dan 12 BSR2 dengan beberapa sifat kimia tanah pada lahan pertanaman tebu

\begin{tabular}{ccc}
\hline \multirow{2}{*}{ Variabel } & \multicolumn{2}{c}{ Koefisien korelasi (r) } \\
\cline { 2 - 3 } & Popul asi cacing tanah & Biomassa cacing tanah \\
\hline Amatan 9 BSR2 & $0,43^{\text {tn }}$ \\
pH tanah & $0,43^{\text {tn }}$ & $0,37^{\text {tn }}$ \\
C-organik & $-0,09^{\text {tn }}$ & $0,33^{\text {nn }}$ \\
Suhu tanah & $-0,17^{\text {tn }}$ & $0,24^{\text {tn }}$ \\
Kadar air tanah & & $-0,24^{\text {tn }}$ \\
\hline Amatan 12 BSR2 & $0,30^{\text {tn }}$ & $-0,02^{\text {tn }}$ \\
C-organik & $-0,13^{\text {tn }}$ & $-0,15^{\text {tn }}$ \\
pH tanah & $0,02^{\text {tn }}$ & $0,10^{\text {tn }}$ \\
Suhu tanah & $0,44^{\text {tn }}$ & $0,51^{\text {tn }}$ \\
Kadar air tanah &
\end{tabular}

Keterangan: ${ }^{\mathrm{tn}}=$ tidak berpengaruh nyata, $\mathrm{BSR} 2=$ bulan setelah ratoon 2.

kandungan C-organik tanah. Hal ini sejalan dengan pernyataan Utomo (1995); franzeluebers dkk.,(1995) dalam Buchari 2002), yang menerangkan bahwa pengaruh perlakuan olah tanah terhadap beberapa sifat tanah seperti C-mik, C-organik dan N-total tanah baru terlihat setelah beberapa tahun. Hal ini diperkuat dengan hasil penelitian Logsdon et al., (1999) dalam Makalew (2001), yang melaporkan bahwa setelah 16 tahun, penerapan sistem OTM baru memberikan jumlah Corganik (pada permukaan $5 \mathrm{~cm}$ ) yang lebih banyak dibandingkan pada lahan yang diolah.

\section{KESIMPULAN}

Berdasarkan hasil penelitian ini dapat disimpulkan bahwa (1) Sistem olah tanah tidak berpengaruh terhadap populasi dan biomassa cacing tanah pada pertanaman tebu ratoon 2. (2) Pengaplikasian mulsa bagas meningkatkan populasi dan biomassa cacing tanah pada pertanaman tebu ratoon 2. (3) Terdapat 2 famili cacing tanah yang didapat dari hasil identifikasi, yaitu famili Megascolecidae dan famili Glossoscolecidae. (4) Tidak terdapat interaksi antara sistem olah tanah dan aplikasi mulsa bagas terhadap populasi dan biomassa cacing tanah. 


\section{SANWACANA}

Ucapan terima kasih disampaikan kepada PT. Gunung Madu Plantation Lampung Tengah dan YNU Jepang yang telah memberikan dana izin untuk dapat melakukan penelitian.

\section{DAFTAR PUSTAKA}

Batubara, M.H. 2012. Pengaruh Sistem Olah Tanah dan Aplikasi Mulsa Bagas pada Lahan Pertanaman Tebu Terhadap Populasi dan Biomassa Cacing Tanah pada Pertanaman Tebu Tahun ke 2. Skripsi. Universitas Lampung. Bandar Lampung.

Busyra, B. S. 1995. Agregasi dan Stabilitas Agregat pada Typic Kandiudult dengan Pemberian Bahan Kompos dan Gambut. Prosiding Sem. Nas-V BDP-OTK. Universitas Lampung. Bandar Lampung. Hal 83-89.

Hanafiah, K., I. Anas, Napoleon dan N. Ghoffar. 2005. Biologi Tanah: Ekologi \& Makrobiologi tanah. Ed. 1, cet. 1. PT. Raja Grafindo Persada. Jakarta. $165 \mathrm{hlm}$.
Makalew, A. D. N. 2001. Keanekaragaman Biota Tanah pada Agroekosistem Tanpa Olah Tanah. Makalah Falsafah Sains. IPB. 19 hlm.

Nursyamsi, D. 2004. Beberapa Upaya untuk Meningkatkan Produktivitas Tanah di Lahan Kering. Makalah Pribadi Falsafah Sains Pasca Sarjana. Institut Pertanian Bogor. Bogor. $24 \mathrm{hlm}$.

PT. GMP. 2009. Pengolahan Tanah. www. Gunungmadu.co.id. diakses pada tanggal 12 Maret 2013

Susilo, F.X. dan A. Karyanto. 2005. Methods for Assessment of Below-Ground Biodiversity In Indonesia. Unila. Bandar Lampung. $58 \mathrm{hlm}$.

Tiara, D. M. 2010. Pemanfaatan Limbah Tebu : Perspektif PT. Gunung Madu Plantation. http://koranpdhi.com/buletin-edisi8/edisi8peternakan2.htm. Diakses pada tanggal 20 Febuari 2013 pada pukul 20.00 WIB.

Utomo, M. 1995. Reorientasi Kebijakan Sistem Olah Tanah. Prosid. Sem. Nas-V. BDP-OTK. Bandar Lampung. Hal 1-7. 